\title{
Pengaruh Aplikasi Kompos Gulma Siam Chromolaena odorata terhadap Produksi Senyawa Metabolit Sekunder sebagai Ketahanan Tanaman pada Tanaman Cabai
}

\author{
Vira Kusuma Dewi1), Nugroho Susetya Putra2), Benito Purwanto2), Santika Sari3), \\ Sri Hartati1), Lilian Rizkie1) \\ 1)Departemen Hama Penyakit Tanaman, Fakultas Pertanian, Universitar Padjadjaran \\ 2)Departemen Hama Penyakit Tanaman, Fakultas Pertanian, Universitas Gajah Mada \\ Jl. Flora, Bulaksumur, Karangmalang, Caturtunggal, Kec. Depok, Sleman, DIY \\ 3)Departemen Budidaya Pertanian, Fakultas Pertanian, UNPAD \\ Jl. Raya Bandung Sumedang Km 21 Jatinangor \\ Korespondensi: vira.kusuma.dewi@unpad.ac.id
}

\begin{abstract}
Chromolaena odorata (L.) is a organic material as potential compost and botanical pesticides since it compounds have the potential as a pesticides is secondary metabolite. The aim of this research was to know the effects of siam weed Chromolaena odorata compost on production of secondary metabolites in the chili. The experiment was arranged in complete randomized design consisted of four treatments (no fertilizer, cow manure, siam weed compost and inorganic fertilizers) and four replications. The research was done by comparing the chemical content of leaves analyzed by Gas Chromatography-Mass Spectrometry (GC-MS) and phytochemical test. This study was conducted from September 2010 to Februari 2011, in the green house of Departement Plant Pest \& Diseases, Faculty of Agriculture. In order to the extraction and characterization of secondary metabolites was conducted at the Laboratory of Chemistry, Universitas Gadjah Mada. Overall, the results of study showed that $C$. odorata compost could give positive effect on production of secondary metabolites as follow terpenoid, alkaloid, steroid and flavonoid on chili.
\end{abstract}

Keywords: Chili, Chromolaena odorata, compost, secondary metabolites

\section{PENDAHULUAN}

Cabai merupakan salah satu tanaman hortikultura yang telah lama dibudidayakan di Indonesia. Berdasarkan data statistik pertanian, Indonesia pernah tercatat sebagai negara pengekspor cabai walaupun jumlah ekspornya seringkali berfluktuasi. Beberapa kendala yang mempengaruhi keberadaan mutu cabai merah (Capsicum annum L.) sehingga produksi setiap tahunnya sering mengalami fluktuasi adalah serangan organisme pengganggu tanaman (OPT) dan masalah pengelolaan budidaya tanaman cabai (Dewi dkk., 2018). Oleh karena itu, berbagai usaha untuk mendukung peningkatkan produksi cabai sangat diperlukan.

Beberapa upaya telah dilakukan dalam usaha untuk meningkatkan produksi cabai, salah satunya dengan pemanfaatan bahan organik baik sebagai pupuk ataupun pestisida nabati. Menurut Fauzi dkk., (2018), penam- bahan bahan organik mampu menambah keberadaan unsur hara makro dan mikro didalam tanah sebagai sumber zat makanan bagi tanaman. Salah satu sumber bahan organik yang berpotensi sebagai pupuk dan pestisida nabati adalah gulma siam Chromolaena odorata (L) King \& H.E. Robinson.

Menurut Hadi (2008), gulma siam sangat melimpah keberadaanya dan merupakan gulma liar yang belum dimanfaatkan secara optimal sebagai bahan organik dalam peningkatan produksi tanaman. Menurut Sirinthipaporn \& Jiraungkoorskul (2017), gulma siam memiliki kandungan metabolit sekunder yaitu alkaloid, flavanoid, saponin, tanin dan seskuiterpenoid. Kandungan metabolit sekunder tersebut memiliki sifat toksik yang mampu menghambat aktivitas makan, dan berpotensi sebagai bahan pestisida, sehingga dapat dimanfaatkan untuk pengendalian hama yang ramah lingkungan. 
Berdasarkan beberapa kajian diatas, maka pada penelitian ini bertujuan untuk mengetahui komposisi senyawa metabolit sekunder yang terbentuk akibat aplikasi kompos gulma siam pada tanaman cabai.

\section{METODOLOGI}

\subsection{Alat dan Bahan}

Alat yang digunakan dalam percobaan meliputi perangkat pengambilan sampel tanaman dan gunting tanaman, sarung tangan karet, perangkat ekstraksi dan perangkat uji fitokimia.

Bahan yang digunakan yaitu tanah, kompos gulma siam, pupuk kohe sapi, pupuk NPK, benih cabai, polibag dan sampel tanaman. Sampel tanaman yang digunakan berasal dari tanaman dengan empat jenis perlakuan yaitu kompos gulma siam (40 ton per ha), pupuk kohe sapi (40 ton per ha), pupuk NPK, dan tanpa pupuk, selanjutnya perlakuan masing-masing diulang sebanyak empat kali. Adapun terkait proses karakterisasi dan ekstraksi tanaman dilakukan di Laboratorium Kimia Organik, FMIPA, UGM.

\subsection{Pembuatan kompos gulma siam}

Tahap pengomposan berlangsung selama 3 minggu. Pada proses awal yang dilakukan adalah pengumpulan bahan hijauan gulma siam. Selanjutnya, daun $C$. odorata dicacah halus, ditimbang, kemudian dihamparkan dan ditambahkan air hingga basah serta dicampur rata. Selanjutnya, ditaburi stardeck sebanyak 6.25 g yang digunakan untuk $25 \mathrm{~kg}$ gulma siam dan dicampur rata. Secara rutin, tiap seminggu sekali dilakukan pembalikkan bahan kompos dan penambahan gula pasir untuk memberikan nutrisi bagi dekomposer. Selain itu, penambahan air secukupnya dilakukan untuk menjaga kelembaban.

\subsection{Penanaman dan pemeliharaan tanaman}

Benih cabai yang digunakan adalah Galur OP 9 perbanyakan tahun 2009 Blok B3. Pada tahap persemaian, bibit yang sudah berumur empat minggu setelah semai kemudian diseleksi untuk ditanam. Pemeliharaan tanaman meliputi penyiraman, pengajiran, pembumbunan, dan penyiangan. Selain itu, penggunaan pupuk yang digunakan telah disesuaikan dengan penghitungan yang ada.

\subsection{Analisis Gas Chromatography-Mass Spectrometry (GC-MS)}

Sampel yang diuji adalah tanaman yang diberikan perlakuan jenis pupuk yaitu kompos gulma siam, pupuk kohe, NPK dan tanpa pupuk. Pada tahap analisis ini diharapkan dapat mengetahui komposisi kandungan metabolit sekunder yang dimiliki oleh setiap sampel tanaman sebagai bentuk mekanisme ketahanan suatu tanaman. Sampel daun cabai/bagian tanaman sebanyak 10 gram dimaserasi dengan menggunakan ethanol $70 \%$ sebanyak $70 \mathrm{ml}$ sebagai pelarut polar, kemudian digojlok dengan menggunakan alat selama 2 hari. Selanjutnya, hasil maserasi tersebut dianalisis dengan menggunakan GC-MS. Kondisi operasi GC-MS yang dipakai yaitu kolom Rastek Rxi-5MS (95\% dimetilpolisiloksan dan $5 \%$ difenilpolisiloksan), panjang: 30 meter, diameter 0,25 $\mathrm{mm}$, tebal lapisan $0,5 \mu \mathrm{m}$, gas pembawa Helium dan sistem pengionan EI $70 \mathrm{eV}$.

\section{$2.5 \quad$ Uji Fitokimia}

\subsubsection{Uji Golongan Senyawa Terpenoid (Lieberman-Burchard) dan Steroid}

Ekstrak dimasukkan sedikit dalam tabung reaksi kecil, lalu dikocok dengan sedikit eter. Lapisan eter diambil lalu diteteskan pada plat tetes dan dibiarkan sampai kering, setelah kering ditambahkan 2 tetes asam asetat anhidrat dan satu tetes sulfat pekat. Apabila terbentuk warna oranye, merah atau kuning berarti positif terpenoid, tetapi bila terbentuk warna hijau berarti positif steroid.

\subsubsection{Uji Golongan Senyawa Flavonoid}

Ekstrak ditambahkan serbuk $\mathrm{Mg}$, lalu ditambahkan asam klorida pekat. Apabila 
terbentuk warna oranye, merah, atau kurang berarti positif flavonoid.

\subsubsection{Uji Golongan Senyawa Alkaloid}

Pereaksi Dragendoff. Ekstrak ditotolkan pada plat KLT, lalu disemprot dengan reagen Dragendoff. Apabila ada noda yang memberikan warna oranye atau merah diduga positif alkaloid.

Pereaksi Meyer. Daun segar dirajang halus, lalu dibasahi dengan alkohol, lalu digerus kemudian ditambahkan sedikit pasir dan gerus. Selanjutnya, penambahan $10 \mathrm{ml}$ kloroform amoniak $0,05 \mathrm{~N}$, digerus lagi. Selanjutnya, hasil disaring dengan kapas, lalu diambil dengan pipet dan dimasukkan ke dalam tabung reaksi besar, ditambahkan $5 \mathrm{ml}$ asam sulfat $2 \mathrm{~N}$, lalu dikocok. Lapisan asam diambil dan dimasukkan ke dalam tabung reaksi yang kecil lalu ditambahkan 1 tetes reagen meyer. Apabila terbentuk endapan putih berarti positif alkaloid.

\subsection{Analisis data}

Data pengamatan yang telah diperoleh dianalisis secara deskriptif.

\section{HASIL DAN PEMBAHASAN}

\subsection{Serapan N, P, dan $\mathrm{K}$}

Analisis kandungan senyawa tanaman menggunakan metode kromatografi gasspektrometri massa (GC-MS) dan uji fitokimia sederhana untuk mendukung penggolongan senyawa-senyawa yang telah teridentifikasi. Pada uji fitokimia ini dilakukan analisis golongan senyawa terpenoid, alkaloid, steroid dan flavonoid yang berperan dalam pertahanan tanaman terhadap organisme penganggu tumbuhan (OPT).

Tabel 1. Komposisi kimia ekstrak daun cabai dengan perlakuan pupuk NPK

\begin{tabular}{cclcr}
\hline $\begin{array}{c}\text { No. } \\
\text { Puncak }\end{array}$ & $\begin{array}{c}\text { Waktu retensi } \\
\text { (menit) }\end{array}$ & \multicolumn{1}{c}{ Nama Senyawa } & $\begin{array}{c}\text { Indeks } \\
\text { Kemiripan }\end{array}$ & $\begin{array}{c}\text { Persentase } \\
(\%)\end{array}$ \\
\hline 1 & 11.258 & Alpha-Guaiene & 89 & 8,77 \\
2 & 11.762 & Alpha-Patchoulene & 86 & 5,62 \\
3 & 12.411 & delta-Guaiene & 87 & 5,63 \\
4 & 14.687 & Patchouli alcohol & 93 & 34,31 \\
5 & 15.431 & 2-metil-3-(1-metilethenil)-cyclohexanol & 76 & 3,14 \\
6 & 15.817 & Limonene dioxide & 78 & 2,95 \\
7 & 16.992 & 1-eicosyne & 83 & 4,38 \\
8 & 17.479 & Metil hexadecanoate & 96 & 5,03 \\
9 & 17.914 & Asam n-hexadecanoic & 94 & 10,39 \\
10 & 18.192 & Etil hexadecanoate & 79 & 2,23 \\
11 & 19.276 & Metil octadec-9-enoate (hit\#2) & 91 & 8,27 \\
12 & 19.508 & Metil eicosanoate & 83 & 1,14 \\
13 & 19.911 & Asam 9-Octadecenoic (Z) & 90 & 8,13 \\
\hline
\end{tabular}

Keterangan : Identifikasi senyawa didasarkan pada kemiripan spektrum massa dari Wiley library dengan persen kemiripan paling mendekati dengan target

Menurut Ambika \& Poornima (2004), metabolit sekunder tanaman digolongkan sebagai allelokimia yaitu suatu senyawa yang dikeluarkan oleh individu atau spesies untuk mempengaruhi pertumbuhan, kebugaran, prilaku atau populasi dari individu atau spesies lain. Unsur hara tanah makro seperti
Nitrogen, Kalium, material organik dan Carbon organik memiliki hubungan erat dengan pembentukan metabolit sekunder pada pertanaman. Berdasarkan Tabel 1, pada esktrak daun cabai dengan perlakuan pupuk NPK teriden-tifikasi 13 senyawa. Puncak kromatogram nomor 4 dengan waktu retensi 
$\left(t_{R}\right) 14.687$ menit memiliki persentase relatif $34,51 \%$.

Berdasarkan NIST dan Wiley library, spektra massa tersebut mirip dengan spektra massa patchouli alkohol dengan Similarity Index (SI) sebesar 93\% dan termasuk dalam golongan seskuiterpenoid. Selain itu, terdapat tiga puncak lain yang memiliki SI $90 \%$ atau lebih yaitu metil hexadecanoate dan metil octadec-9-enoate dimana keduanya termasuk dalam golongan ester. Selain itu, spektra massa lain adalah asam n-hexadecanoic dan asam 9-Octadecenoic termasuk dalam golongan asam lemak (Tabel 1).
Ekstrak daun tana-man cabai dengan perlakuan kompos gulma siam yang dapat dideskripsikan sebanyak 12 senyawa (Tabel 2). Puncak kromatogram nomor 1 dengan waktu retensi $\left(t_{R}\right) 14.708$ menit dan memiliki persentase relatif $50,09 \%$ diper-kirakan merupakan puncak dari patchouli alkohol yang termasuk dalam golongan seskuiterpenoid. Puncak kromatogram lain-nya dengan indeks kemiripan $90 \%$ atau lebih adalah nomor $8,9,10,11$ dan 12 . Spektra massa yang dimiliki oleh puncak 8, 10 dan 11 termasuk golongan ester, sedangkan puncak 9 dan 12 masing-masing dari golongan asam lemak dan steroid.

Tabel 2 Komposisi kimia ekstrak daun cabai dengan perlakuan kompos Gulma Siam

\begin{tabular}{cclcr}
\hline $\begin{array}{c}\text { No. } \\
\text { Puncak }\end{array}$ & $\begin{array}{c}\text { Waktu Retensi } \\
\text { (menit) }\end{array}$ & \multicolumn{1}{c}{ Nama Senyawa } & $\begin{array}{c}\text { Indeks } \\
\text { Kemiripan }\end{array}$ & $\begin{array}{c}\text { Persentase } \\
(\%)\end{array}$ \\
\hline 1 & 14.708 & Patchouli alkohol & 93 & 50.09 \\
2 & 15.449 & Nopinone & 75 & 3.61 \\
3 & 15.725 & Tetradecanoid acid & 86 & 0.99 \\
4 & 15.831 & Limonene dioxide & 78 & 3.91 \\
5 & 16.246 & Limonene dioxide & 79 & 1.74 \\
6 & 17.297 & Dihydro-4-carene & 79 & 2.77 \\
7 & 17.402 & 1,5,9-Decatriene,2,3,5,8-tetramethyl & 86 & 7.27 \\
8 & 17.493 & Metil hexadecanoate & 90 & 8.86 \\
9 & 17.933 & Asam n-hexadecanoic & 93 & 12.13 \\
10 & 19.162 & Metil octadec-9-enoate (hit\#2) & 91 & 0.91 \\
11 & 19.307 & Metil octadec-9-enoate (hit\#2) & 94 & 5.99 \\
12 & 23.316 & 3,12-dihidroksikolestan-24-one (hit\#2) & 90 & 1.73 \\
\hline
\end{tabular}

Keterangan : Identifikasi senyawa didasarkan pada kemiripan spektrum massa dari Wiley Library dengan persen kemiripan paling mendekati dengan target.

Pada ekstrak daun cabai dengan perlakuan pupuk kohe telah teridentifikasi 12 senyawa, dalam puncak kromatogram adalah nomor 4 yang memiliki indeks kemiripan $96 \%$ (Tabel 3). Spektra massa pada no puncak 4 menunjukkan asam n-hexadecanoic yang tergolong asam lemak. Selain itu, terdapat 5 puncak lain yang memiliki indeks kemiripan $90 \%$ atau lebih yaitu nomor 1, 2, 3, 5 dan 9. Adapun berdasarkan spektra massanya maka masing-masing termasuk dalam golongan ester untuk puncak nomor 1, 2, 3 dan 5, sedangkan puncak nomor 9 tergolong alkena (Tabel 3).
Analisis senyawa lainnya dilakukan terhadap kandungan minyak atsiri pada daun cabai. Berdasarkan Tabel 4, ekstrak daun cabai dengan perlakuan tanpa pupuk telah teridentifikasi 7 senyawa. Puncak kromatogram yaitu nomor 2, namun spektra massanya memiliki indeks kemiripan dibawah 90\%. Sedangkan puncak yang lainnya adalah nomor 3, 4, dan 5 dengan persentase relatifnya sebesar $8,44 \%, 17,83 \%$ dan 15,63\%. Ketiga puncak tersebut spektra massanya adalah Metil hexadecanoate yang tergolong dalam ester. 
Tabel 3. Komposisi kimia ekstrak daun cabai dengan perlakuan pupuk kotoran hewan (sapi)

\begin{tabular}{cllrr}
\hline $\begin{array}{c}\text { No. } \\
\text { Puncak }\end{array}$ & $\begin{array}{c}\text { Waktu retensi } \\
\text { (menit) }\end{array}$ & \multicolumn{1}{c}{ Nama Senyawa } & $\begin{array}{c}\text { Indeks } \\
\text { Kemiripan }\end{array}$ & $\begin{array}{c}\text { Persentase } \\
(\%)\end{array}$ \\
\hline 1 & 17,274 & Metil hexadecanoate & 90 & 6,51 \\
2 & 17,377 & Metil hexadecanoate & 90 & 9,07 \\
3 & 17,477 & Metil hexadecanoate & 93 & 5,05 \\
4 & 17,906 & n-hexadecanoic acid & 96 & 38,33 \\
5 & 19,276 & Metil octadec-9-enoate (hit\#2) & 91 & 1,21 \\
6 & 19,693 & Metil eicosanoate & 83 & 16,87 \\
7 & 19,808 & Asam 9-octadecenoic & 83 & 4,03 \\
8 & 19,898 & Asam 9-octadecenoic & 83 & 12,04 \\
9 & 20,832 & (E)-9-eicosene & 94 & 3,78 \\
10 & 27,841 & 3,12-dihidroksikolestan-24-one (hit\#2) & 71 & 3,11 \\
\hline Keterangan : Identifikasi senyawa didasarkan pada kemiripan spektrum massa dari & Wiley Library dengan persen
\end{tabular}

Tabel 4. Komposisi kimia ekstrak daun cabai tanpa perlakuan pupuk

\begin{tabular}{cclcr}
\hline $\begin{array}{c}\text { No. } \\
\text { Puncak }\end{array}$ & $\begin{array}{c}\text { Waktu retensi } \\
\text { (menit) }\end{array}$ & \multicolumn{1}{c}{ Nama Senyawa } & $\begin{array}{c}\text { Indeks } \\
\text { Kemiripan }\end{array}$ & $\begin{array}{c}\text { Persentase } \\
(\%)\end{array}$ \\
\hline 1 & 6,442 & $\begin{array}{l}\text { Terpineol(4-methyl-1-(1-isopropyl)-3- } \\
\text { cyclohexen-1-ol) }\end{array}$ & 88 & 5,28 \\
2 & 12,741 & Myristcin & 85 & 35,06 \\
3 & 17,270 & Methyl hexadecanoate & 90 & 8,44 \\
4 & 17,375 & Methyl hexadecanoate & 90 & 17,83 \\
5 & 17,480 & Methyl hexadecanoate & 94 & 15,63 \\
6 & 19,267 & Methyl octadec-9-enoate (hit\#2) & 84 & 14,89 \\
7 & 19,508 & Methyl eicosanoate & 83 & 2,87 \\
\hline
\end{tabular}

Keterangan : Identifikasi senyawa didasarkan pada kemiripan spektrum massa dari Wiley library dengan persen kemiripan paling mendekati dengan target

Pada Tabel 5 ditampilkan perbedaan komposisi kimia dari masing-masing ekstrak tanaman akibat perlakuan jenis pupuk yang

berbeda pada sehingga terlihat jelas faktor penambahan unsur hara terhadap komposisi senyawa yang tersusun dalam tanaman.

Tabel 5 Perbedaan komposisi kimia ekstrak daun cabai dengan perlakuan jenis pupuk

\begin{tabular}{|c|c|c|c|c|}
\hline No. & Gulma Siam & NPK & Kotoran Sapi & Kontrol \\
\hline 1. & Patchouli alkohol & Patchouli alkohol & $\begin{array}{l}\text { Metil } \\
\text { hexadecanoate }\end{array}$ & Metil hexadecanoate \\
\hline 2. & Metil hexadecanoate & Metil hexadecanoate & $\begin{array}{l}\text { Asam } \\
\text { n-hexadecanoic }\end{array}$ & \\
\hline 3. & $\begin{array}{l}\text { Asam } \\
\text { n-hexadecanoic }\end{array}$ & n-hexadecanoic acid & $\begin{array}{l}\text { Metil octadec-9- } \\
\text { enoate (hit\#2) }\end{array}$ & \\
\hline 4. & $\begin{array}{l}\text { Metil octadec-9- } \\
\text { enoate (hit\#2) }\end{array}$ & $\begin{array}{l}\text { Metil octadec-9- } \\
\text { enoate (hit\#2) }\end{array}$ & $(E)$-9-eicosene & \\
\hline 5. & $\begin{array}{l}\text { 3,12- } \\
\text { dihydroxycholestan- } \\
\text { 24-one (hit\#2) }\end{array}$ & $\begin{array}{l}\text { Asam } \\
\text { 9-Octadecenoic (Z) }\end{array}$ & & \\
\hline
\end{tabular}


Pada analisis kandungan senyawa tanaman ini, selain menggunakan deteksi GCMS maka dilakukan pula uji fitokimia untuk mendukung penggolongan senyawa-senyawa yang telah teridentifikasi. Tabel 6 menunjukkan hasil uji fitokimia yang dilakukan terhadap golongan senyawa terpenoid, alkaloid, steroid dan flavonoid yang berperan dalam pertahanan tanaman terhadap serangga OPT.

Tabel 6 Hasil Uji Fitokimia Golongan Senyawa Terpenoid, Alkaloid, Flavonoid dan Steroid

\begin{tabular}{lcccc}
\hline \multicolumn{1}{c}{ Perlakuan } & Terpenoid & Alkaloid & Flavonoid & Steroid \\
\hline NPK & ++ & + & +++ & ++ \\
Gulma Siam & +++ & +++ & ++ & +++ \\
Kotoran Sapi & - & + & ++ & ++ \\
Kontrol & + & + & + & + \\
\hline
\end{tabular}

Keterangan : (+) rendah, (++) sedang, (+++) tinggi; Tanda simbol menunjukkan tingkat kepekatanwarna dari hasil uji fitokimia

Berdasarkan analisis kandungan senyawa tanaman dengan deteksi GC-MS dan uji fitokimia dapat dijelaskan bahwa pada ekstrak daun cabai yang diberi perlakuan kompos gulma siam dan NPK ditemukan senyawa patchouli alkohol yang termasuk dalam golongan seskuiterpenoid (Tabel 5). Menurut Harborne (1993), seskuiterpenoid biasanya terdapat pada tanaman dalam bentuk senyawa atsiri penyebab bau pada sayuran atau buah dan bersifat volatil (mudah menguap). Scoonhoven et. al. (2005) juga menegaskan bahwa seskuiterpenoid bersifat deteren yang berperan dalam menghambat aktivitas makan dan proses peletakkan telur oleh serangga herbivor.

Ekstrak daun cabai yang diberi perlakuan kompos gulma siam, NPK dan pupuk kohe sapi mempunyai kesamaan kandungan senyawa lain yaitu asam n-hexadecanoic, sedangkan senyawa asam 9 octadecanoic pada perlakuan kontrol. Menurut Trenkamp et al., (2004), senyawa asam n-hexadecanoic dan asam 9 octadecanoic termasuk dalam golongan asam lemak. Golongan asam lemak memiliki fungsi untuk memperkuat membran sel pada tumbuhan tingkat tinggi. Selain itu, peran asam lemak lainnya adalah melindungi tanaman dari kekeringan, kehilangan mineral penting dan senyawa volatil dari tumbuhan serta masuknya patogen ke dalam jaringan tanaman.
Lebih lanjut, ekstrak daun cabai dari perlakuan kompos gulma siam, NPK, kotoran sapi dan kontrol juga mengandung senyawa dari golongan ester yaitu metil hexanoate dan metil octadec-9-enoate. Pada penelitian Batovska et al., (2009), metil hexadecanoat dan metil octadec-9-enoate memiliki peranan penting dalam komunikasi kimia antara tanaman dengan spesies serangga tertentu.

Berdasarkan analisis GC-MS pada ekstrak daun cabai yang diberi perlakuan kompos gulma siam, senyawa 3-12-dehidroksikolestan 24-one termasuk dalam golongan steroid.. Menurut Hanani dkk., (2005), steroid merupakan senyawa organik bahan alam yang dihasilkan oleh organisme melalui metabolit sekunder. Senyawa ini banyak ditemukan pada jaringan hewan dan tanaman tingkat tinggi bahkan terdapat pula pada beberapa tanaman tingkat rendah seperti jamur. Salisbury \& Ross (1995) juga menambahkan bahwa steroid mempunyai fungsi yang penting bagi tumbuhan, yaitu untuk perpanjangan organ, diferensiasi jaringan pembuluh, kesuburan, dan perkembangan.

Senyawa lain yang ditemukan hanya pada perlakuan pupuk kohe adalah (E)-9-eicosene yang termasuk dalam golongan alkena. Menurut Harborne (1987), alkena merupakan senyawa hidrokarbon yang memiliki ikatan rangkap dua antar atom karbonnya, dan juga mengikat atom hidrogen. Senyawa alkena ini 
dibentuk secara alami oleh tumbuhan dan berperan sebagai hormon. Alkena diketahui dapat merangsang pematangan buah dan pembukaan kuncup bunga. Selain itu, terkait dengan interaksi antar spesies maka diketahui bahwa (Z)-9-Eicosene berperan dalam komunikasi antar spesies.

Berdasarkan analisis GC-MS dan uji fitokimia yang telah dideskripsikan diatas maka diketahui bahwa senyawa-senyawa yang terdapat pada beberapa sampel tanaman yang diberikan perlakuan kompos gulma siam dan jenis pupuk lainnya hampir memiliki kandungan metabolit sekunder yang serupa dan termasuk dalam terpenoid, alkaloid, steroid dan flavonoid dengan kadar yang berbeda-beda. Hal ini disebabkan respon yang diberikan oleh tanaman terhadap serangga herbivor juga berbeda-beda tergantung dengan kandungan senyawa yang berkerja dalam mendukung mekanisme ketahanan tanaman.

Menurut Dicke \& Loon, (2000) bahwa respon tanaman dalam mengeluarkan senyawa volatil akibat kerusakan tanaman yang disebabkan oleh aktivitas makan serangga herbivor dapat berbeda dalam jumlah maupun komposisi kimia dari senyawa yang dihasilkan. Selain itu, Gershenson (1984) dalam Jansson (2003) menyatakan bahwa tingkat atau kadar metabolit sekunder tanaman dapat berubah pada saat kondisi tanaman mendapat cekaman dari lingkungan misalnya cekaman air atau defisiensi unsur kalium dapat memicu peningkatan kandungan alkaloid pada beberapa tanaman. Sedangkan defisiensi unsur nitrogen dapat memicu penurunan kandungan alkaloid pada tanaman.

\section{KESIMPULAN}

Berdasarkan hasil percobaan, maka dapat disimpulkan yaitu :

1. Kandungan metabolit sekunder yang terdeteksi berdasarkan hasil uji GC-MS dan fitokimia terhadap ekstrak daun tanaman cabai yang diberi perlakuan berupa terpenoid, alkaloid, steroid dan flavonoid.

2. Aplikasi kompos gulma siam dapat memberikan pengaruh positif terhadap senyawa kimia pembentuk metabolit sekunder untuk ketahanan tanaman.

\section{DAFTAR PUSTAKA}

Ambika, S.R. and S. Poornima. 2006. Allelochemicals from Chromolaena odorata (L) King and Robinson for increasing crop productivity. Chromolaena in the Asia Pacific Region. $19-24$.

Batovska DI, I.T. Todorova, S.S. Popov. 2009. Seasonal variations in the leaf surface composition of field grown grapevine plants. J Serb Chem Soc 74(11): 12291240.

Dewi, V.K., N.S. Putra, B. Purwanto, S. Hartati, S. Sari. 2018. Aplikasi kompos gulma siam Chromolaena odorata terhadap sifat kimia tanah dan performa tanaman cabai. Soilrens, 16 (1): 65 72.

Dicke, M. and Van Loon. 2000. Multitrophic effects of herbivore-induced plant volatiles in an evolutionary context. Entomol. Exp. Appl. 97: 237249.

Harborne, J. B. 1993. Metode Fitokimia: Penuntun Cara Modern Menganalisis Tumbuhan. ITB Press, Bandung

Hadi, M. 2008. Pembuatan kertas anti rayap ramah lingkungan dengan memanfaatkan ekstrak daun kirinyuh (Eupatorium odoratum). Jurnal BIOMA. 6 (2): 12-18.

Jansson, J. 2003. The Influence of Plant Fertilisation on Plant-Aphid-Parasitoid Interactions. Departement of Entomology Uppsala. Swedish 
University of Agricultural Sciences. Dissertation.

Fauzi, R., Octaviani., R. Yunior, V.K. Dewi, S. Sari, S. Hartati, D.H. Yudistira, Y.U. Sandi. 2018. Pengaruh pupuk organik gulma siam (Chromolaena odorata L.) dan ampas bungkil mimba (Azadiracta indica A.Juss) pada Sifat kimia tanah dan performa tanaman padi hitam. Soilrens 16(2): 57 - 64 .

Salisbury, F.B. \& C.W. Ross. 1995. Plant Physiology $4^{\text {th }}$ Edition. Wadsworth Publishing Company, Belmont. California

Scoonhoven, L.M, V, Loon, \& M. Dicke. 2005. Insect Plant Biology. Oxford University Press, London.

Sirinthipaporn, A and Jiraungkoorskul, W. 2017. Wound healing property review of siam weed, Chromolaena odorata. Pharmacogn Rev 11(21):35-38

Trenkamp S, Martin W, Tietjen K. 2004. Specific and differential inhibition of very-long-chain fatty acid elongases from Arabidopsis thaliana by different herbicides. Proceedings of the National Academy of Science of USA, 101 (32): 11903-11908. 